\title{
Bio-emulsifying and biodegradation activities of syringafactin producing Pseudomonas spp. strains isolated from oil contaminated soils
}

\author{
Oumaima Zouari • Didier Lecouturier • Alice Rochex • Gabrielle Chataigne • \\ Pascal Dhulster • Philippe Jacques • Dhouha Ghribi
}

Received: 25 October 2017/ Accepted: 17 October 2018/Published online: 2 November 2018

(C) Springer Nature B.V. 2018

\begin{abstract}
Pseudomonas strains isolated from oil contaminated soils were screened for biosurfactant production. Three out of eleven Pseudomonas isolates were selected for their high emulsifying activity (E24 value on $n$-hexadecane $\sim 78 \%)$. These isolates (E39, E311 and E313) were identified as members of the $P$. putida group using phenotypical methods and a molecular approach. To identify the chemical nature of produced biosurfactants, thin layer chromatography and MALDI-ToF mass spectrometry analysis were carried out and revealed lipopeptides belonging to the syringafactin family. The activity of the produced biosurfactants was stable over a $\mathrm{pH}$ range of 6-12, at
\end{abstract}

O. Zouari - D. Lecouturier · A. Rochex ·

G. Chataigne · P. Dhulster · P. Jacques

Univ. Lille, INRA, ISA, Univ. Artois, Univ. Littoral Côte d'Opale, EA 7394 - ICV - Institut Charles Viollette, 59000 Lille, France

O. Zouari · D. Ghribi

Unit of Enzyme and Bioconversion, National School of Engineers, Soukraroad, 3038 Sfax, Tunisia

P. Jacques

TERRA Teaching and Research Centre, Microbial Processes and Interactions, GemblouxAgroBio Tech Liege University, 5030 Gembloux, Belgium

D. Lecouturier $(\bowtie)$

Institut Charles Viollette, Université de Lille,

PolytechLille, Avenue Paul Langevin,

59655 Villeneuve d'Ascq Cedex, France

e-mail: Didier.Lecouturier@univ-lille.fr high salinity (10\%) and after heating at $80{ }^{\circ} \mathrm{C}$. Tests in contaminated sand micro-bioreactors showed that the three strains were able to degrade diesel. These results suggest the potential of these syringafactin producing strains for application in hydrocarbon bioremediation.

Keywords Pseudomonas - Biosurfactant . Bioemulsifier · Biodegradation · Lipopeptide

\section{Introduction}

Surfactants are amphiphilic chemical compounds, i.e. they contain both hydrophobic and hydrophilic groups, that accumulate preferentially at the interface between fluid phases with different degrees of polarity and hydrogen bonding such as oil/water or air/water interfaces. They are used industrially as emulsifiers, wetting, dispersing and foaming agents. Microbial surfactants, known as biosurfactants, are produced by diverse microorganisms such as bacteria, fungi and yeasts, and are structurally diverse (Desai and Banat 1997; Karanth et al. 1999; Lang 2002; Mulligan 2005). They are grouped into low molecular weight compounds including glycolipids, lipopeptides and phospholipids, and into high molecular weight polymers including proteins, lipoproteins, polysaccharides and lipopolysaccharides (Ron and Rosenberg 2002).

In comparison to synthetic surfactants, biosurfactants offer several advantages mainly due to their high 
biodegradability, which makes them more ecofriendly. Furthermore, some of these molecules have a good stability on extreme conditions of $\mathrm{pH}$, temperature and salinity (Marchant and Banat 2012). These properties render them appropriate for many application fields such as polluted soils bioremediation (Cameotra and Makkar 2010; Pacwa-Płociniczak et al. 2011), agriculture (Sachdev and Cameotra 2013), food industry (Campos et al. 2013), and animal and human health (Cameotra and Makkar 2004; Rodrigues et al. 2006).

Pseudomonas spp. are well-known for their ability to produce biosurfactants mainly rhamnolipids and lipopeptides (Mulligan 2005). Rhamnolipids, glycolipids which consist of one or two molecules of rhamnose linked to one, two or three molecules of $\beta$ hydroxyfatty acid (Abdel-Mawgoud et al. 2010), are some of the best studied biosurfactants. Lipopeptides are powerful biosurfactants that are composed of a lipid tail linked to a short linear or cyclic oligopeptide. They are structurally very diverse, depending on the configuration, type and number of the amino acids in the peptide and on the composition and length of the fatty acid. They are divided into several families: the majors are viscosin, amphisin, orfamide, putisolvin, tolaasin, entolysin, syringopeptin, syringomycin and syringafactin families (Raaijmakers et al. 2010; Roongsawang et al. 2011). Rhamnolipids and lipopeptides are implicated in many important bacterial functions, including antimicrobial activity, swarming motility, attachment, biofilm formation and effect on bioavailability allowing the solubilisation of insoluble compounds by increasing wettability and emulsification of water. Biosurfactants can also protect cells from toxic compounds and heavy metals by encapsulating them into micelles (Ron and Rosenberg 2001; Van Hamme et al. 2006). Biosurfactant producing Pseudomonas are commonly found in different environments including soil and the rhizosphere (Fechtner et al. 2011), particularly in hydrocarbon-contaminated soils where they facilitate hydrocarbon degradation (Bodour et al. 2003; Bento et al. 2005; D'aes et al. 2010; Saikia et al. 2012; Mohammed et al. 2015) and on plants where they can be beneficial or harmful for their host (D'aes et al. 2010). For these reasons, Pseudomonas are good candidates for discovering new biosurfactants. The present study aimed to screen Pseudomonas spp. strains isolated from hydrocarbon contaminated soil for their potential to produce biosurfactants/bioemulsifers. The most potent isolates were tested for application in diesel biodegradation.

\section{Materials and methods}

Isolation of Pseudomonas strains

Bacterial colonies were isolated from an oil-contaminated soil from an auto-mechanical workshop, in the area of Sfax, Tunisia. $500 \mathrm{~g}$ of soil samples were collected from the surface, at 5 and $10 \mathrm{~cm}$ of depth. $1 \mathrm{~g}$ of each sample was mixed with $10 \mathrm{~mL}$ physiological water by vortexing for $10 \mathrm{~min}$; then several dilutions were prepared on physiological water, spread on an LB agar medium and incubated at $30{ }^{\circ} \mathrm{C}$ for $24 \mathrm{~h}$. Colonies were selected on the basis of colony morphology, transferred separately on cetrimide agar a selective medium for Pseudomonas isolation, and incubated at $30{ }^{\circ} \mathrm{C}$ for $24 \mathrm{~h}$. Pseudomonas bacteria were preserved on cryotubes containing $40 \%$ of glycerol solution and stored at $-20{ }^{\circ} \mathrm{C}$ for short preservation and $-80^{\circ} \mathrm{C}$ for long preservation.

Bacterial growth conditions and cell-free supernatant preparation

Colony growth was performed on Tryptic Soy Agar plates streaked with frozen stocked cells at a temperature of $30{ }^{\circ} \mathrm{C}$ for $24 \mathrm{~h}$. Liquid culture was performed in Tryptic Soy Broth (pancreatic digest of casein $17 \mathrm{~g} \mathrm{~L}^{-1}$; peptic digest of soybean meal $3 \mathrm{~g} \mathrm{~L}^{-1}$; Dglucose $2.5 \mathrm{~g} \mathrm{~L}^{-1}$; sodium chloride $5 \mathrm{~g} \mathrm{~L}^{-1}$; dipotassium hydrogen phosphate $2.5 \mathrm{~g} \mathrm{~L}^{-1}$ ) at $30{ }^{\circ} \mathrm{C}$ for $72 \mathrm{~h}$ with shaking on $160 \mathrm{rpm}$. A $10 \mathrm{~mL}$ preculture was inoculated with an isolated colony after $24 \mathrm{~h}$ of incubation. Then, $0.1 \mathrm{~mL}$ of the $24 \mathrm{~h}$ preculture served to inoculate a $100 \mathrm{~mL}$ culture which was incubated in the same conditions for $48 \mathrm{~h}$. Broth culture was centrifuged for $10 \mathrm{~min}$ at $10,000 \times g$. The obtained supernatant was sterilized through a $0.22 \mu \mathrm{m}$ Millipore PES filter membrane and stored at $4{ }^{\circ} \mathrm{C}$ for biological tests.

Preparation of crude extract of biosurfactants

Biosurfactants were precipitated overnight at $4{ }^{\circ} \mathrm{C}$ by adding $\mathrm{HCl}(6 \mathrm{M})$ to the free cell supernatant to a $\mathrm{pH}$ of 2 (Cooper and Goldenberg 1987; Peypoux et al. 
1999). The mixture was centrifuged at $10,000 \times g$ for $20 \mathrm{~min}$ and then the pellet was resuspended in ultrapure water. Finally, the $\mathrm{pH}$ was adjusted to 7 with $\mathrm{NaOH}(1 \mathrm{M})$ and the crude extract was lyophilized using a Heto Power Dry PL 9000 freezedryer (Jouan Nordic, Allerod, Denmark), according to the following steps: $1 \mathrm{~h}$ at $-30{ }^{\circ} \mathrm{C}, 5 \mathrm{~h}$ at $-10{ }^{\circ} \mathrm{C}$, $5 \mathrm{~h}$ at $0{ }^{\circ} \mathrm{C}, 5 \mathrm{~h}$ at $20{ }^{\circ} \mathrm{C}, 5 \mathrm{~h}$ at $35^{\circ} \mathrm{C}$. Freeze-drying was carried out under a residual pressure of 15 mbar. For utilisation, lyophilized crude extract was then solubilized in ultrapure water so that to obtain the adequate concentrations ( $1 \%$ or $0.1 \% \mathrm{w} / \mathrm{v})$ and stored at $4{ }^{\circ} \mathrm{C}$.

Screening for biosurfactant production

\section{Drop collapse test}

To identify biosurfactant-producing strains, a drop collapsing test was carried out according to Bodour and Miller-Maier (1998). $2 \mu \mathrm{L}$ of paraffin oil was added to each well of a 96-well microliter plate and allowed to equilibrate for $1 \mathrm{~h}$ at room temperature. Then, $5 \mu \mathrm{L}$ of cell-free supernatant of Pseudomonas spp. isolates were added on oil surface. The result was observed after $1 \mathrm{~min}$. The cultures which gave flat drops were scored as positive, while the cultures that gave rounded drops which pointed-out a deficiency of biosurfactant production were scored as negative.

\section{Surface tension and $F_{C M C}$ measurement}

The surface tension was measured on cell-free supernatants and on the crude extracts of Pseudomonas spp. isolates using a tensiometer (TD1 LAUDA, LaudaKönigshofen, Germany) according to the Du Noüy ring method. Pure water was used as control, giving a surface tension value of $72 \mathrm{mN} \mathrm{m}^{-1}$. Critical micelle concentration (CMC) is specified as the concentration at which the micelle formation is initiated in the solution containing the amphiphilic compound. CMC represents the intersection of linear component of the curve drawn between the surface tension and the biosurfactant concentration. In our case, surface tension measurements were performed on seven different dilutions of supernatants in ultrapure water: $1 / 20 ; 1 / 10 ; 1 / 5 ; 1 / 41 / 2 ; 1$ at room temperature which provides the dilution of the supernatant at which the CMC is reached (Chakraborty et al. 2011). The $\mathrm{F}_{\mathrm{CMC}}$ value is determined as an indirect estimation of the CMC by the determination of dilution value where there was a sharp rise in the surface tension (Cooper and Zajic 1980).

\section{Oil displacement test}

This assay was performed according to Morikawa et al. (2000). $40 \mathrm{~mL}$ of distilled water were placed on the surface of a large Petri dish with $150 \mathrm{~mm}$ in diameter, followed by adding $15 \mu \mathrm{L}$ of crude oil (diesel) on the water surface, and $20 \mu \mathrm{L}$ of the isolate culture supernatants on the centre of the oil film. Then, the diameter of the clear halo visualized under visible light was measured after $30 \mathrm{~s}$. If biosurfactants are present, the oil will be displaced resulting in an oil free clearing zone. A larger diameter of oil depicts a higher activity of biosurfactant.

\section{Emulsion index determination}

Emulsifying activity was measured according to the Cooper and Goldenberg (1987) method. $4 \mathrm{~mL}$ of biosurfactant crude extract were mixed with $4 \mathrm{~mL}$ of $n$-hexadecane and vortexed at high speed for $2 \mathrm{~min}$. The mixture was allowed to stand for $24 \mathrm{~h}$ before measurement and the emulsion index was defined as follows:

$E 24(\%)=\frac{\text { height of emulsion layer }}{\text { total height }} \times 100$

Identification of bacterial strains

To characterise the phenotypic properties of isolated strains, tests including morphological characterisation, Gram staining, oxidase activity and carbohydrate fermentation profile determined by API 20 NE tests (Biomerieux; Marcy l'Etoile, France) were performed. Each fermentation profile was processed by the APIWEB software database for identification. Genotypic characterisation was performed as follows. Genomic DNA was isolated from a one-night bacterial culture using the Wizard Genomic Purification DNA Kit (Promega Corp., Madison, WI, USA) following the prescribed standard protocol.). The whole $16 \mathrm{~S}$ rRNA gene was amplified by polymerase chain reaction $(\mathrm{PCR})$ using primers $\mathrm{S} 1$ (5-AGAGTTTGAT C(A,C)TGGCTCAG-3) and S2 (5-GG(A,C)TACCTT 
GTTACGA(T,C)TTC-3). The PCR reaction was performed with the following mixture: $5 \mu \mathrm{L}$ of extracted genomic DNA (200 ng $\mu \mathrm{L}^{-1}$ ), $2.5 \mu \mathrm{L}$ of each primer (20 mM), $25 \mu \mathrm{L}$ of PCR Master Mix (Thermo Fisher Scientific Fermentas, Vilnius, Lithuania) and ddH2O were mixed up to a final volume of $50 \mu \mathrm{L}$. PCR thermal cycling was carried out using a thermal cycler as follows: a first denaturation of the DNA at $94{ }^{\circ} \mathrm{C}$ for $3 \mathrm{~min}$, than 30 cycles of denaturation at $94{ }^{\circ} \mathrm{C}$ for $40 \mathrm{~s}$, primer annealing at $55^{\circ} \mathrm{C}$ for $50 \mathrm{~s}$, and primer synthesis step at $72{ }^{\circ} \mathrm{C}$ for $12 \mathrm{~min}$. The PCR products were subjected to agarose gel electrophoresis and purified using a QIA quick DNA gel purification kit (Qiagen, Hilden, Germany). Then, purified PCRs were introduced into Escherichia coli JM109 using the pGEMT Easy vector kit (Promega Corp). Transformed cells were selected on Luria-Bertani (LB) solid medium supplemented with $100 \mathrm{~g} \mathrm{~L}^{-1}$ of ampicillin. Plasmids were isolated from transformant colonies using QIAprep plasmid extraction kit protocol (Qiagen). Restriction endonuclease analysis of the plasmids was carried-out using EcoRI (Thermo Fisher Scientific Fermentas). Cloned products were sequenced and analysed as above. The sequencing of resulting cloned product was performed by the Custom Sequencing Service of Eurofins Genomics (Ebersberg, Germany) based on cycle sequencing technology on ABI PRISM 3730XL. Two sequencing reactions generating both forward and reverse sequences between 900 and $1000 \mathrm{pb}$ were required to cover the length of the 16S rRNA gene (about $1500 \mathrm{pb}$ ). Sequences were trimmed and assembled as previously described (El Arbi et al. 2016). The 16S rRNA gene sequences obtained from the isolate E39, E311 and E313 were compared with other bacterial sequences using NCBI megaBLAST (http://blast.ncbi.nlm.nih. gov/Blast.cgi) for their pairwise identities. Then, a maximum-likelihood phylogenetic tree was built with PhymL on SeaView version 4. All sequences were submitted to the GenBank database [accession numbers: MG183696 (E39), MG183695 (E311), and MG188738 (E313)].

\section{Thin layer chromatography}

The type of biosurfactant was preliminary determined by using a thin layer chromatography (TLC) analysis. A volume of $40 \mu \mathrm{L}$ of crude biosurfactant extracted from E39, E311 and E313 strains supernatant was spotted into three silica gel plates (F-254; Fisher) using CAMAG automatic TLC sampler. Samples were developed using $\mathrm{CHCl}_{3}: \mathrm{CH}_{3} \mathrm{OH}: \mathrm{H}_{2} \mathrm{O}$ (65:15:2 $\mathrm{v} / \mathrm{v} / \mathrm{v})$ as a mobile phase. Then the plates were airdried, sprayed with standard reagents and heated at $105{ }^{\circ} \mathrm{C}$ during $5 \mathrm{~min}$. Ninhydrin reagent $(0.5 \mathrm{~g}$ ninhydrin $+100 \mathrm{~mL}$ acetone) was used for peptide detection and anthrone reagent $(1 \mathrm{~g}$ anthrone $+5 \mathrm{~mL}$ sulphuric acid $+95 \mathrm{~mL}$ ethanol) for sugar detection.

\section{Mass spectrometry analysis}

Matrix-Assisted Laser Desorption Ionization-Time of Flight Mass Spectrometry (MALDI-ToF-MS) was used to detect the production of lipopeptides on whole cells and in liquid cultures; i.e. in the cell-free supernatant and in the biosurfactant crude extract. For whole cell analyses, an isolated colony of bacteria grown on TSA solid medium was suspended in $10 \mu \mathrm{L}$ of matrix solution $\left(10 \mathrm{mg} \mathrm{mL}^{-1}\right.$ of $\alpha$-cyano-4-hydroxycinnamic acid in $70 \%$ water, $30 \%$ acetonitrile, and $0.1 \%$ TFA). For liquid culture analyses, $1 \mu \mathrm{L}$ of supernatant or crude extract and $1 \mu \mathrm{L}$ of matrix solution were mixed. Then, $1 \mu \mathrm{L}$ of the prepared samples were spotted in a MALDI-ToF MTP 384 target plate (BrukerDaltonik GmbH, Leipzig, Germany) following the dried-droplet preparation method. Molecular mass analyses were carried out with an Ultraflex MALDI-ToF/ToF mass spectrometer (Bruker, Bremen, Germany) equipped with a smartbeam laser. The masses were measured in reflector positive mode in $\mathrm{m} / \mathrm{z}$, range between 800 and $2000 \mathrm{Da}$. Analyses were conducted with an accelerating voltage of $25 \mathrm{kV}$ and a deflection mode of matrix suppression at $\mathrm{m} / \mathrm{z} 750 \mathrm{Da}$. The laser power was adjusted to around $30 \%$ to above the threshold of ionization.

Effect of $\mathrm{pH}$, temperature and salinity on biosurfactant stability

Biosurfactant stability was studied by testing the liquid surface tension reducing activity and the emulsifying activity of the biosurfactant crude extract solution $(0.1 \% \mathrm{w} / \mathrm{v})$. To test their thermal stability, the biosurfactant solution was set at constant temperatures ranging from 4 to $100{ }^{\circ} \mathrm{C}$ for $24 \mathrm{~h}$, and then cooled at room temperature. The $\mathrm{pH}$ effect was tested by adjusting the $\mathrm{pH}$ of the crude biosurfactant solution 
into a range of 2-12 using $\mathrm{HCL}$ or $\mathrm{NaOH}$ solutions and different buffers: $50 \mathrm{mmol} \mathrm{L}{ }^{-1}$; citrate buffer $(\mathrm{pH}$ 3.0-6.0), $50 \mathrm{mmol} \mathrm{L}^{-1}$ phosphate buffer (pH 6.0-8.0), and $50 \mathrm{mmol} \mathrm{L}^{-1}$ glycine-NaOH buffer $(\mathrm{pH}$ 9.0-12.0). The effect of salinity on the biosurfactants stability was investigated by adjusting specific concentrations of $\mathrm{NaCl}(2-10 \%$, w/v) of crude biosurfactant solution. The surface tension and E24 values for each treatment were performed as described above.

\section{Diesel biodegradation assays}

Plastic buckets (7 $\mathrm{cm}$ diameter, $15 \mathrm{~cm}$ height) were prepared as bioreactor systems for diesel biodegrading assays for each biosurfactant producing strains. Each bioreactor contains $200 \mathrm{~mL}$ of sand and is spoiled with $10 \%(\mathrm{v} / \mathrm{v})$ of diesel oil sterilized by filtration through a $0.2 \mu \mathrm{m}$ membrane and inoculated with $20 \mathrm{~mL}$ of an overnight bacterial culture and then thoroughly mixed together to achieve complete artificial contamination. A bioreactor inoculated with Rhodococcus erythropolis T902.1 as a reference strain (Weekers et al. 1999) was used as positive control and a bioreactor fed with free bacteria culture medium as negative control. Bioreactors were continuously flushed by 0.3 bar air and drawn towards a perforate pipe atop the systems. Buckets were daily percolated with M9 minimal medium lacked of carbon sources and having as basis the following composition: $\mathrm{Na}_{2} \mathrm{HPO}_{4} 6 \mathrm{~g} \mathrm{~L}^{-1}, \mathrm{KH}_{2}$ $\mathrm{PO}_{4} 3 \mathrm{~g} \mathrm{~L}^{-1}, \mathrm{NaCl} 0.5 \mathrm{~g} \mathrm{~L}^{-1}, \mathrm{NH}_{4} \mathrm{Cl} 1 \mathrm{~g} \mathrm{~L}^{-1}$ and $\mathrm{MgSO}_{4} 0.24 \mathrm{~g} \mathrm{~L}^{-1}$. All bioreactors were incubated at $30{ }^{\circ} \mathrm{C}$ for 28 days. Bioreactor contents were aerated by sand turnover every $48 \mathrm{~h}$. Diesel degradation was followed every week by collecting $1 \mathrm{~g}$ of contaminated s and mixing it with $2 \mathrm{~mL}$ of toluene solvent to measure its optical density by spectrophotometer at $420 \mathrm{~nm}$ according to Rahman et al.(2002). Removal percentage of total petroleum hydrocarbon $(\% \mathrm{TPH})$ was determined as follows:

$\% T P H=\left(\frac{O D i-O D x}{O D i}\right) \times 100$

These experiments were carried out in triplicate.

Chemical oxygen demand (COD) measurement

Diesel mineralization in the sand bioreactor was measured after $28 \mathrm{~h}$ of incubation by the test of chemical oxygen demand (COD), using total oxidation of organic carbon with sulphuric acid and potassium dichromate. Around $30 \mathrm{mg}$ of spoiled sand was introduced in COD digestion vials (Hach, USA). Complete oxidation occurred for $2 \mathrm{~h}$ at $150{ }^{\circ} \mathrm{C}$. After cooling, absorbance was measured at $565 \mathrm{~nm}$ and compared to standards of potassium hydrogenophtalate. Then, sand was washed with distilled water and dried at $105{ }^{\circ} \mathrm{C}$ for $24 \mathrm{~h}$ and weighted. COD results were expressed in $\mathrm{g}$ of oxygen per $\mathrm{g}$ of sand. COD removal was calculated as follows:

COD removal $=\left(\frac{C O D \text { day } 0-C O D \text { day } 28}{C O D \text { day } 0}\right) \times 100$

\section{Results and discussion}

Isolation and screening of biosurfactant producing Pseudomonas

Totally eleven Pseudomonas strains were isolated on cetrimide-agar plates from samples of oil contaminated soil collected in an auto-mechanical workshop. Morphological observation of these strains showed gram negative bacilli, motile bacteria. Strains were screened for biosurfactant activity by performing drop collapsing tests, surface tension measurements and oil displacement tests on their cell-free supernatant, and emulsion index tests on their biosurfactant crude extract $(1 \% \mathrm{w} / \mathrm{v})$ as these methods are commonly used to detect biosurfactant production by microorganisms (Youssef et al. 2004). Drop collapse test was first used as a simple and rapid method. Five isolates designated by E33b, E38b, E39, E311 and E313 were positive (Table 1) which indicated their potential to produce biosurfactants. Drop collapse assay results did not always correlate with the liquid surface tension reducing activity (Mohammed et al. 2015). So, the cell-free supernatants of all isolated strains were characterised by tensiometry (Table 1). The five drop-collapse-positive isolates (E33b, E38b, E39, E311 and E313) had the highest liquid surface tension reducing activity, the surface tensions of cell-free supernatant cultures were lowered to less than $35 \mathrm{mN} \mathrm{m}^{-1}$ which is a criterion of good surfactant (Mulligan 2005). These values were comparable to those reported for culture supernatants of diverse 
Table 1 Assessment of biosurfactant and emulsifying activities of Pseudomonas spp. isolates obtained from oil contaminated soil

\begin{tabular}{lllll}
\hline Isolate & Drop collapse test & Surface tension $\left(\mathrm{mN} \mathrm{m}^{-1}\right)$ & Oil displacement $(\mathrm{mm})$ & Emulsion index $($ E24) \\
\hline E33a & - & $55.9 \pm 0.2$ & nd & nd \\
E33b & + & $30.3 \pm 1.2$ & $16.2 \pm 1.1$ & $53 \pm 0.5 \%$ \\
E36 & - & $47.4 \pm 0.8$ & nd & nd \\
E37 & - & $50.3 \pm 0.8$ & nd & nd \\
E38a & - & $49.1 \pm 0.2$ & nd & nd \\
E38b & + & $30.3 \pm 1.6$ & $17.0 \pm 1.1$ & $62.7 \pm 1.1 \%$ \\
E39 & + & $29.9 \pm 0.7$ & $19.3 \pm 0.6$ & $79.0 \pm 2 \%$ \\
E310 & - & $52.9 \pm 0.5$ & nd & nd \\
E311 & + & $34.0 \pm 0.6$ & $19.0 \pm 2.7$ & $78.0 \pm 0.2 \%$ \\
E312 & - & $39.6 \pm 0.6$ & nd & nd \\
E313 & + & $30.3 \pm 0.6$ & $19.3 \pm 0.6$ & $79.0 \pm 0.4 \%$ \\
\hline
\end{tabular}

nd not determined

biosurfactant producing Pseudomonads, the lowest surface tensions were observed between 24 and $30 \mathrm{mN} \mathrm{m}^{-1}$ (Nielsen et al. 2002; Fechtner et al. 2011; Mohammed et al. 2015). Rhamnolipids can reduce the tension surface below $30 \mathrm{mN} \mathrm{m}^{-1}$ (Lang and Wullbrandt, 1999; Müller et al. 2012). The lipopopeptides produced by Pseudomonas, such as viscosin and arthrofactin, are some of the most efficient biosurfactants by reducing liquid surface tension to $26.5 \mathrm{mN} \mathrm{m}^{-1}$ ( $\mathrm{Neu}$ et al. 1990) and $24 \mathrm{mN} \mathrm{m}^{-1}$ (Morikawa et al. 1993) respectively. For comparison, the best known lipopeptide, surfactin produced by Bacillus subtilis, reduced liquid surface tension to $27 \mathrm{mN} \mathrm{m}^{-1}$ (Arima et al. 1968). The surface tension of the 5 strains free cell supernatants remains stable up to the 1/4th dilution (Fig. 1). This indicated that the concentrations of biosurfactants in all the supernatants were above their $\mathrm{F}_{\mathrm{CMC}}$ value (Fig. 1). Afterwards, oil displacement and emulsification tests were carried out with the five most surfaceactive strains. Isolates E39, E311 and E313 performed best in all assays. Their supernatant caused a higher oil displacement and had the highest emulsion index with $n$-hexadecane, i.e. $79 \pm 2 \%$ for E39 and E313, and $78 \pm 2 \%$ for E311. These values are high compared to the emulsion index with $n$-hexadecane found for Pseudomonas strains, producing rhamnolipids: 70-80\% (Aparna et al. 2012; Saikia et al. 2012; Pacwa-Plociniczak et al. 2014), and for a Pseudomonas strain, producing lipopeptides: $\sim 58 \%$ (de
Fig. 1 Plot of surface tension versus serial cellfree supernatant dilutions of Pseudomonas isolates E33b (filled triangle), E38b (filled diamond), E39 (times symbol), E311 (filled square) and E313 (filled circle) solutions and $\mathrm{F}_{\mathrm{CMC}}$ determination

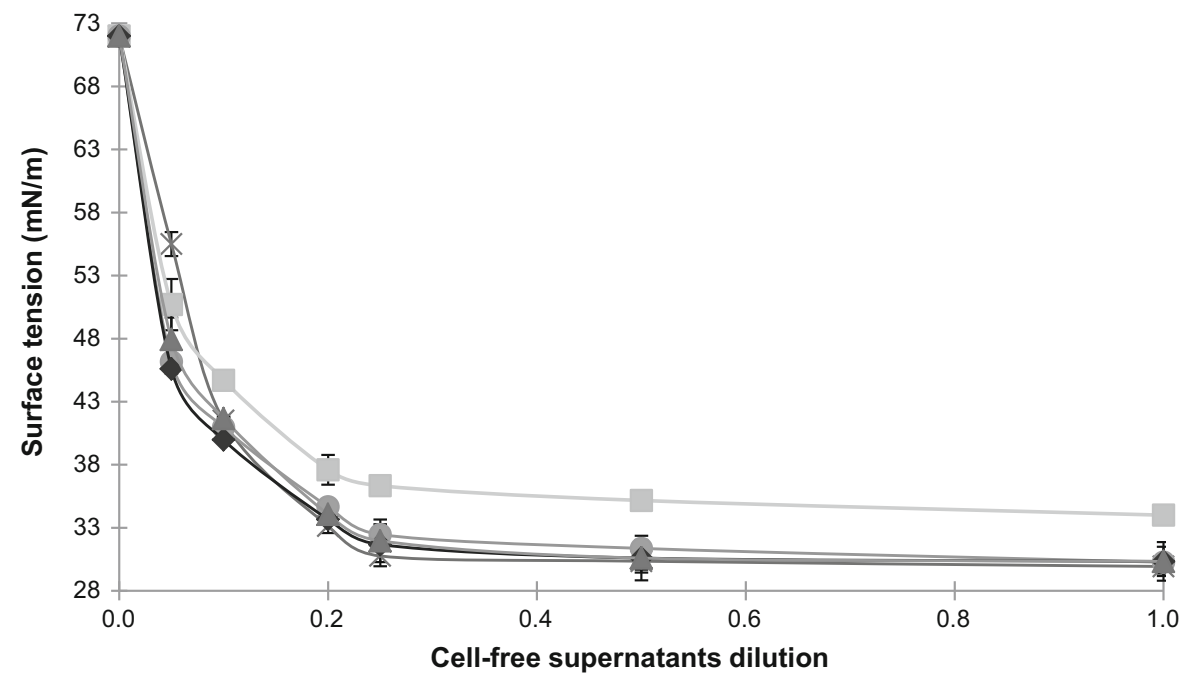


Sousa and Bhosle 2012). Moreover, Pseudomonas purified lipopeptides such as viscosin, massetolide A, putisolvin, amphisin (Bak et al. 2015) and pseudofactins (Janek et al. 2010) were shown to be good emulsifiers of $n$-hexadecane. The emulsions resulting from E39, E311 and E313 biosurfactant addition were stable for more than 1 month; this emulsion stability suggests the application of these molecules as good emulsifier agents in industrial domains. For further characterisation, we selected the isolates E39, E311 and E313 that displayed the best emulsion index.

Identification of biosurfactant producing strains

Biosurfactant producing bacteria were identified using biochemical characterisation tests and molecular identification based on whole 16S rRNA gene sequence BLAST analysis. All the three selected strains showed positive reactions to oxidase and arginine dihydrolase. According to the API $20 \mathrm{NE}$ system, E39 was identified as Pseudomonas spp., E311 and E313 as $P$. putida. The phylogenetic relationships of E39, E311 and E313 strains with closely related type strains of the genus Pseudomonas are shown on the 16S rRNA gene tree (Fig. 2). The 16SrRNA sequence of these three strains were included in the P. putida group as defined by Gomila et al. (2015). The most closely related strains were Pseudomonas sp. DOC19 (99.8\% identity), $P$. donghuensis HYST, $P$. alkylphenolica KL28T and $P$. vranovensis 2B2T (98.7\% identity) which are members of the P. putida group (Merino et al. 2013; Gao et al. 2015; Mulet et al. 2015; Tvrzova et al. 2006). The position of the strains E39, E311 and E313 in a separate branch of the phylogenetic tree with Pseudomonas sp. DOC 19 suggests that all four strains belong to a new species of the Pseudomonas putida group which is frequently represented in soils and in water.

\section{Biosurfactant characterisation}

To gain further perspicacity about the nature of the produced biosurfactant, TLC analysis was performed. For the crude extracts of isolates E39, E311 and E313, TLC revealed red spots showing a positive reaction when ninhydrin was used as visualization agent, which implies the presence of amino acid groups. No reaction occurred with anthrone reagent, which discards the hypothesis that the selected isolates produced glycolipids. They were then examined for their ability to produce lipopeptide biosurfactants by using MALDI-ToF mass spectrometry which is an efficient device for their detection (Vater et al. 2002). Analyses were performed on whole cells grown on TSA solid medium (Fig. 3), on the supernatant of culture in TSB liquid medium and on crude extract (data not shown). In both solid and liquid media, mass spectra of Pseudomonas spp. E39, E311 and E313 revealed series of prominent peaks ranging between $\mathrm{m} / \mathrm{z}, 1090.7$ and 1142.7. All three isolates produce molecules with $\mathrm{m} / \mathrm{z}$ corresponding to syringafactin A $\left(m / z \quad 1104.7 \quad[\mathrm{M}+\mathrm{Na}]^{+}, \quad 1120.7 \quad[\mathrm{M}+\mathrm{K}]^{+,} \quad 1126.7\right.$ $\left.[(\mathrm{M}-\mathrm{H})+2 \mathrm{Na}]^{+}, \quad 1142,7 \quad[(\mathrm{M}-\mathrm{H})+\mathrm{Na}+\mathrm{K}]^{+}\right)$. Syringafactins are octalipopeptides linked to $\mathrm{C} 10$ or C12 fatty acid, Berti et al. (2007) first identified syringafactins A, B, C, D, E and F which were detected in the mass range from $\mathrm{m} / \mathrm{z} 1104.7$ to 1146.7 for sodium adducts and from $\mathrm{m} / \mathrm{z}, 1120.7$ to 1162.7 for potassium adducts. Other members of the syringafactin family, named cichofactins, were identified by Pauwelyn et al. (2013); the exact $\mathrm{m} / z$ of $[\mathrm{M}+\mathrm{Na}]^{+}$of these lipopeptides, are 1131.7 and 1159.7. In this work, mass spectra of three isolates also showed mass peaks at $m / z 1090.7[\mathrm{M}+\mathrm{Na}]^{+}, 1106.7[\mathrm{M}+\mathrm{K}]^{+}$, $1112.7 \quad[(\mathrm{M}-\mathrm{H})+2 \mathrm{Na}]^{+}, \quad 1128,7 \quad[(\mathrm{M}-\mathrm{H})+$ $\mathrm{Na}+\mathrm{K}]^{+}$, separated by $14 \mathrm{Da}$ from mass peaks at $m / z \quad 1104.7 \quad[\mathrm{M}+\mathrm{Na}]^{+}, \quad 1120.7 \quad[\mathrm{M}+\mathrm{K}]^{+,} \quad 1126.7$ $[(\mathrm{M}-\mathrm{H})+2 \mathrm{Na}]^{+}, \quad 1142,7 \quad[(\mathrm{M}-\mathrm{H})+\mathrm{Na}+\mathrm{K}]^{+}$ respectively, suggesting that the corresponding molecules varied from each other by the presence of different amino acid residue in the peptide moiety. The intensities of peaks from $\mathrm{m} / \mathrm{z} 1090.7$ to 1142.7 were lower in the mass profile of strain E311, suggesting it produced lower quantity of syringafactins than strains E39 and E313. The mass profile of strain E39 contained unknown masses from $\mathrm{m} / \mathrm{z} 1162.5$ to 1189.5 which were not present in other strains. Two of these masses probably correspond to the $[\mathrm{M}+\mathrm{Na}]^{+}$ form $(\mathrm{m} / \mathrm{z}, 1173.5)$ and to the $\left.[\mathrm{M}+\mathrm{K}]^{+}\right)$form $(\mathrm{m} / \mathrm{z}$ $1189.5)$ of the same molecule. These differences in mass spectral profiles confirmed that Pseudomonas spp. E39, E311 and E313 strains were different although they produced the same syringafactin like molecules. It is interesting to notice that bacteria of the Pseudomonas putida group isolated in this work produced biosurfactants of the syringafactin family whereas only a strain of Pseudomonas syringae 


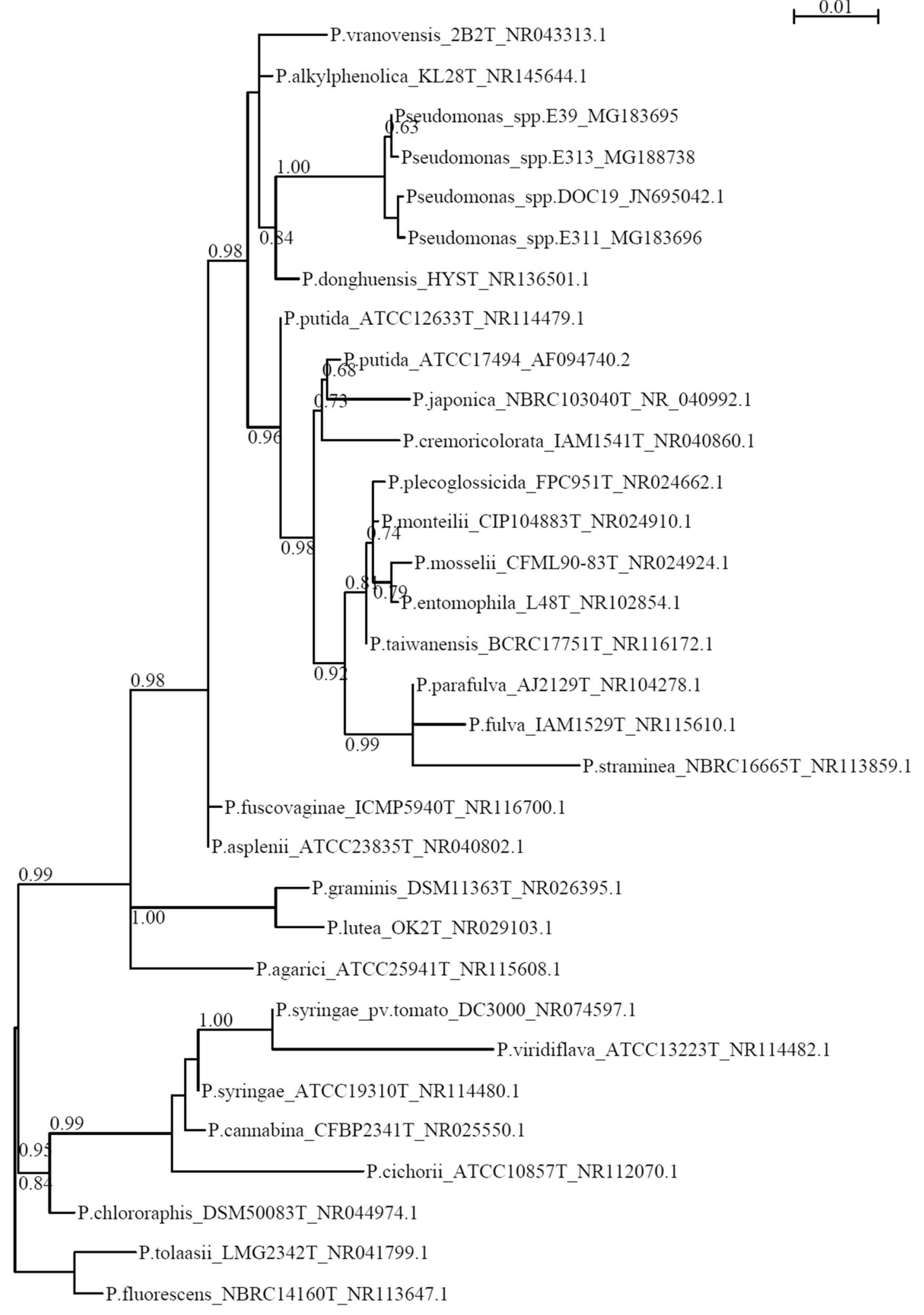


4Fig. 2 Maximum-likelihood phylogenetic tree based on partial 16S rRNA gene sequence analysis showing the relationship of biosurfactant producing isolates with phylogenetically close members of the genus Pseudomonas. The tree was rooted with $P$. tolaassii LMG 2342T and P. fluorescens NRBC 14160T. Branch supports were assessed with the Shimodaira-Hasegawalike approximate likelihood ratio test (SH-aLRT). Only values above 0.6 were displayed

(DC3000) (Berti et al. 2007) and a strain of Pseudomonas cichorii (SF1-54) (Pauwelyn et al. 2013) were reported to produce syringafactins. Syringafactin was shown to have biosurfactant properties and to be involved in the swarming properties of the producing strains (Berti et al. 2007; Pauwelyn et al. 2013). However, this lipopeptide was not studied for its bioemulsifying properties and its role in bioremediation. Biosurfactants known to be produced by $P$. putida include rhamnolipids (Tuleva et al. 2005; Martinez-Toledo et al. 2006; Janek et al. 2013), phospholipids (Janek et al. 2013) and the lipopeptides putisolvins (Kuiper et al. 2004; Kruijt et al. 2009) and white-line-inducing principle (WLIP), a member of the viscosin group (Rokni-Zadeh et al. 2012).

Effect of $\mathrm{pH}$, temperature and salinity on biosurfactant stability

The stability of biosurfactants in different environment conditions such as $\mathrm{pH}$, temperature and salinity is an important factor to study, since it affects directly their applicability. The biosurfactants produced by

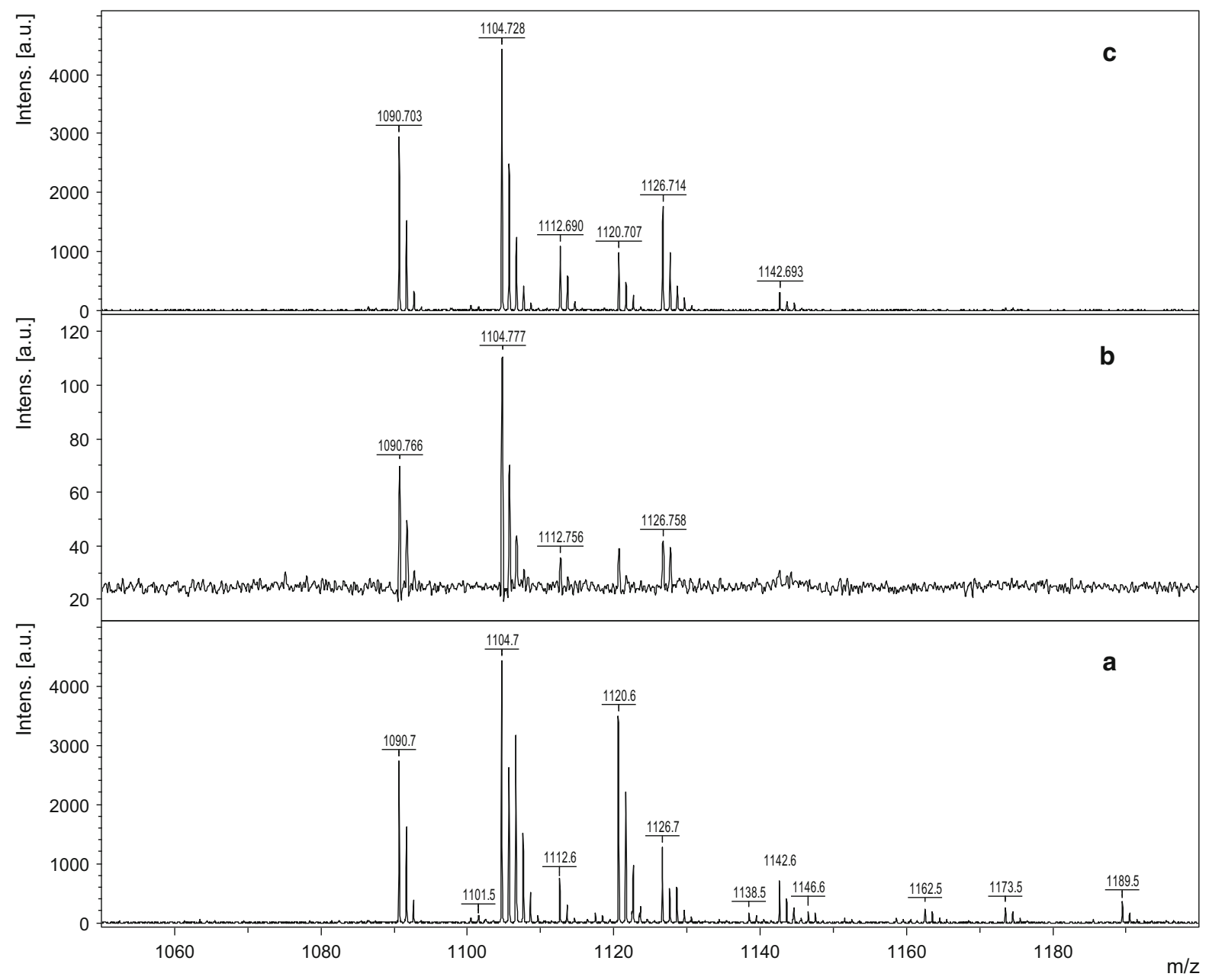

Fig. 3 Whole-cells MALDI-ToF mass spectra of the three selected biosurfactant isolates, a Pseudomonas spp. E39, b Pseudomonas spp. E311. c Pseudomonas spp. E313 
(a)

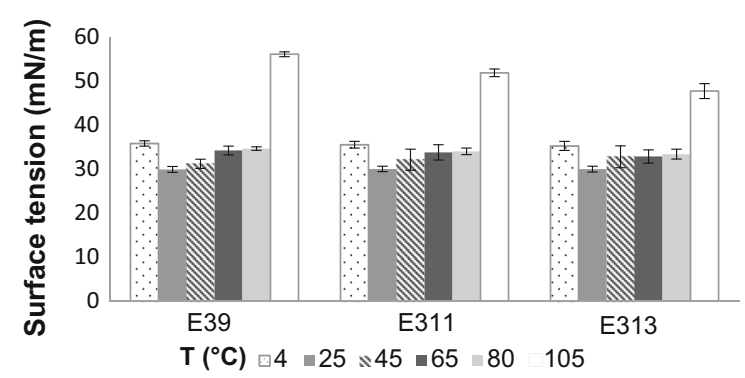

(b)

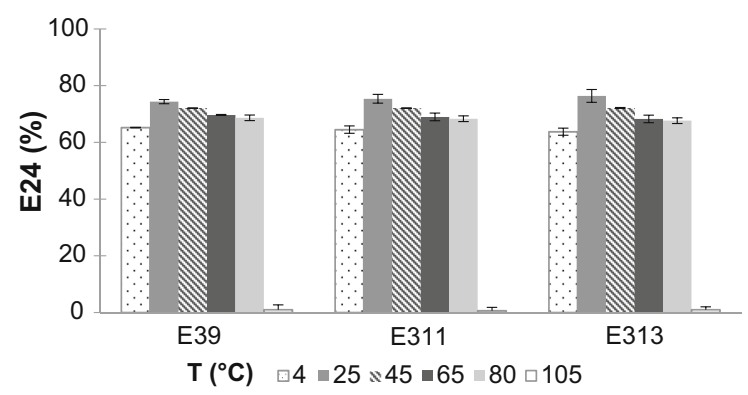

(c)

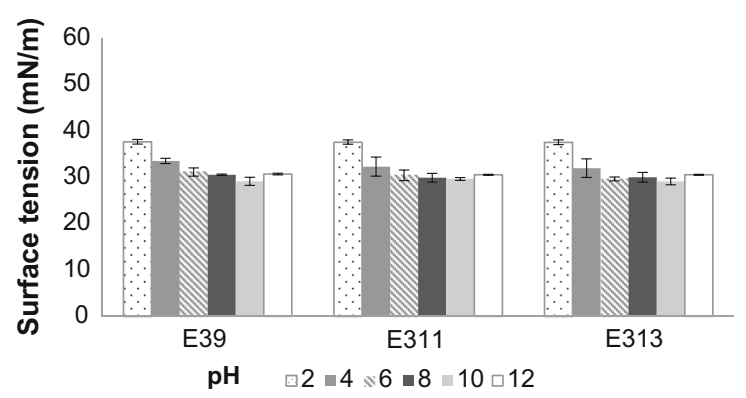

Fig. 4 Study of environmental conditions on biosurfactant crude extracts $(0.1 \% \mathrm{w} / \mathrm{v})$ stability: temperature effect on tensioactive residual activity (a) and emulsifying residual activity (b), $\mathrm{pH}$ effect on tensioactive residual activity (c) and

Pseudomonas spp. E39, E311 and E313 were shown to be thermostable as they retained their activity after a $24 \mathrm{~h}$ treatment at a temperature range of $4-80{ }^{\circ} \mathrm{C}$ (Fig. 4a, b). At $105^{\circ} \mathrm{C}$, the tension surface reducing activity decreased. The thermal resistance of biosurfactants is usually high. Rhamnolipids retain good surface tension reducing and emulsifying activities up to $121{ }^{\circ} \mathrm{C}$ (Abdel-Mawgoud et al. 2009; Aparna et al. 2012; Saikia et al. 2012) and lipopeptidic biosurfactants up to $80{ }^{\circ} \mathrm{C}$ or $100{ }^{\circ} \mathrm{C}$ as those produced by $P$. nitroreducens TSB.MJ10 (de Sousa and Bhosle 2012),

\section{(d)}

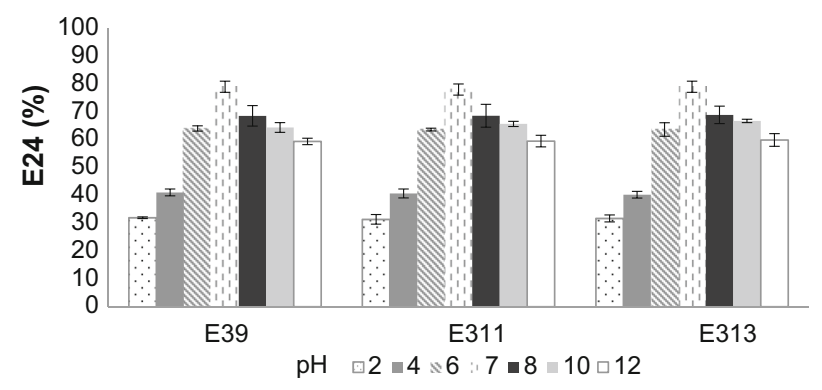

(e)

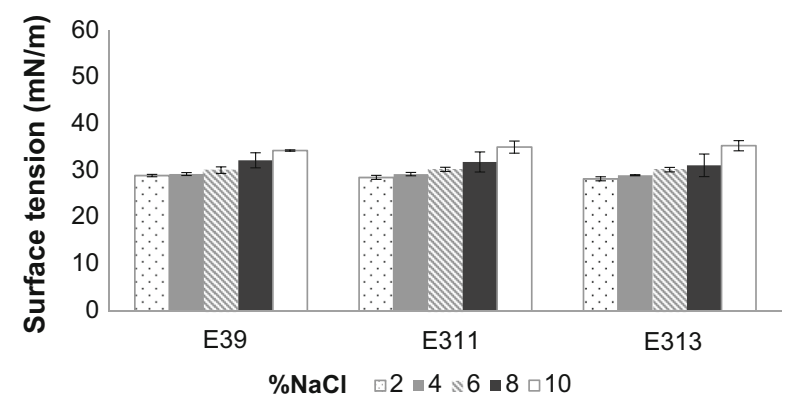

(f)

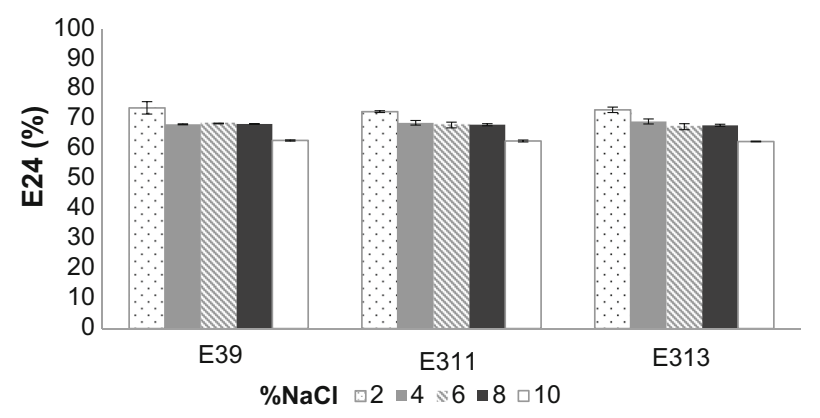

emulsifying residual activity (d), salinity effect on tensioactive residual activity (e) and emulsifying residual activity (f) of biosurfactants produced by E39, E311 and E313 strain

Serratia marcescens NSK-1 (Anyanwu et al. 2011) and Bacillus subtilis DM-03 and DM-04 (Mukherjee 2007). The $\mathrm{pH}$ stability assays showed that the surface tension reducing and emulsifying activity of the tested biosurfactants remained stable over a $\mathrm{pH}$ range of 6-12 (Fig. 4c, d) but was affected by acidic conditions below $\mathrm{pH}$ 4. The alkaline $\mathrm{pH}$ stability of lipopeptidic biosurfactants has been showed by Anyanwu et al. (2011), de Sousa and Bhosle (2012) and Mukherjee (2007). A decrease of emulsifying activity at acid $\mathrm{pH}$ was also observed by de Sousa and Bhosle (2012) and 
Fig. 5 Study of total petroleum hydrocarbon (TPH) biodegradation by E39 (filled square), E311 (filled diamond) and E313 (filled triangle) strains in diesel contaminated sand comparing with

Rhodococcus erythropolis T902.1 used as positive control (filled circle) and a non-inoculated bucket as a negative control (dashed line)

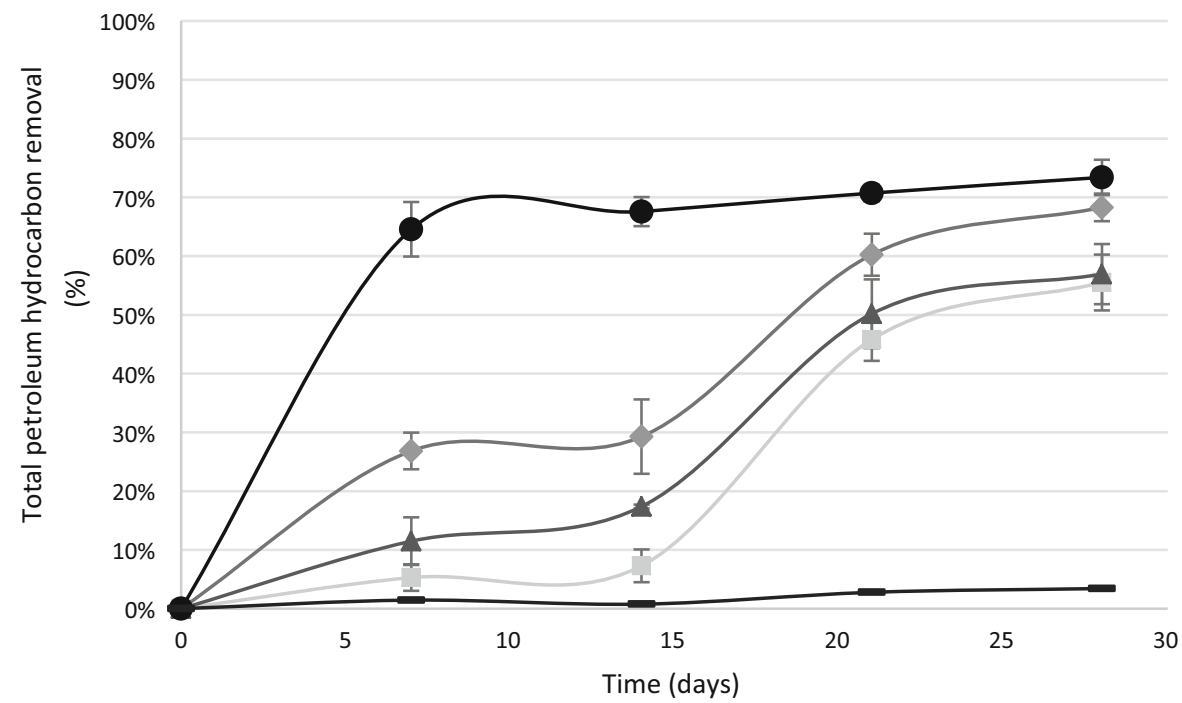

by Khopade et al. (2012) for an undetermined bioemulsifier. It should also be noticed that the biosurfactant solution became turbid under $\mathrm{pH} 4$ as observed by Khopade et al. (2012).The precipitation of biosurfactant could explain the partial loss of the activity. Rhamnolipids show a higher stability to $\mathrm{pH}$ in a range of 2-12 (Abdel-Mawgoud et al. 2009; Aparna et al. 2012; Saikia et al. 2012). The addition of $\mathrm{NaCl}$ up to $10 \%$ only slightly decreased the activity of biosurfactants (Fig. 4e, f). The tolerance of lipopeptidic or rhamnolipidic biosurfactants has been reported up to $20 \%$ or $25 \% \mathrm{NaCl}$ (Anyanwu et al. 2011; de Sousa and Bhosle 2012; Aparna et al. 2012) The stability of the crude biosurfactants in a wide range of temperature, $\mathrm{pH}$ and salinity conditions confirmed their potential to be used in many fields and in particular in bioremediation application.

\section{Diesel biodegradation}

In this experiment, we were interested in finding out if the biosurfactant producing isolates might be able to degrade diesel oil since growth on crude oil is often associated with the production of surfactants. Sand bioreactors were contaminated by diesel oil and inoculated with isolates E39, E311, E313 and Rhodococcus erythropolis T902.1 as positive control. Biodegradation was monitored by both measuring removal percentage of total petroleum hydrocarbons (\% TPH) and COD. In this experiment, strains could only use diesel oil as sole carbon source. At 28 days of biodegradation test, a removal of around $70 \%$ of TPH was achieved in bioreactors inoculated with E311 and $R$. erythropolis T902.1. However, R. erythropolis T902.1 reached this level of biodegradation sooner (14 days). The removal percentage was lower with E39 and E313 (around 55\% of TPH) (Fig. 5). According to mass analyses, strain E311 was the less lipopeptide productive strain whereas its potential for degradation of hydrocarbons was the most effective. There are several hypotheses to be mentioned: (i) the production of biosurfactants is different in the presence of hydrocarbons, (ii) a low production of biosurfactant is sufficient to be effective, (iii) too high production of surfactants could have an inhibitory effect on growth (high hydrocarbons solubility could be toxic for the cell). The removal of COD showed that all strains oxidized diesel in the sand bioreactors (Table 2). The removal of COD of E313 was very close to the removal of TPH which indicates that the

Table 2 Evaluation of diesel degradation by TPH removal and COD removal measurements

\begin{tabular}{lll}
\hline Strain & $\begin{array}{l}\text { TPH removal } \\
(\%)\end{array}$ & $\begin{array}{l}\text { COD removal } \\
(\%)\end{array}$ \\
\hline E39 & $55 \pm 3$ & $37 \pm 10$ \\
E311 & $68 \pm 14$ & $22 \pm 3$ \\
E313 & $57 \pm 19$ & $55 \pm 5$ \\
R. erythropolis & $75 \pm 9$ & $49 \pm 8$ \\
T902.1 & & \\
\hline
\end{tabular}

$T P H$ total petroleum hydrocarbons, $C O D$ chemical oxygen demand 
strain has an efficient diesel mineralization enzymatic potential. The removal of COD was lower than the removal of TPH for the other strains which indicates that diesel is only partially oxidized. These results are comparable with those obtained in other studies (Das and Mukherjee 2007; Mnif et al. 2017) which suggest that these Pseudomonas spp. strains could be useful in bioremediation application. The biosurfactants that they produce could enhance oil biodegradation in soils (Pacwa-Płociniczak et al. 2011).

\section{Conclusion}

This study enabled to select three Pseudomonas spp. isolates from oil contaminated soils for their high emulsifying activities. These isolates (E39, E311 and E313) were closely related to members of the $P$. putida group and their produced biosurfactants were identified as lipopeptides belonging to the syringafactin family. Furthermore, the study showed the high stability of biosurfactants over extreme $\mathrm{pH}$, temperature and salinity conditions and the capacity of syringafactin producing strains to degrade diesel in an artificially contaminated sand. These results suggest the potential of syringafactin for application in bioremediation processes.

Acknowledgements This work was funded by the Ministry of Higher Education and Scientific Research of Tunisia and a scholarship from the region Hauts-de-France. This work was supported by the European Union SMARTBIOCONTROLPOR TFOLIO-Interreg FWVLBIOPROD program, the FEDER program ALIBIOTECH and the CPER project ALIBIOTECH from the region Hauts-de-France. The authors are grateful to the Advanced High Throughput Technologies Platform for Biorefineries Catalysts Design 'REALCAT' for allowing the implementation of MALDI-ToF mass spectrometry analysis. The authors are grateful to Kamel Maaloul, translator and English professor for having proofread the manuscript.

\section{References}

Abdel-Mawgoud AM, Aboulwafa MM, Hassouna NAH (2009) Characterization of rhamnolipid produced by Pseudomonas aeruginosa isolate Bs20. Appl Biochem Biotechnol 157:329-345

Abdel-Mawgoud AM, Lépine F, Déziel E (2010) Rhamnolipids: diversity of structures, microbial origins and roles. Appl Microbiol Biotechnol 86:1323-1336

Anyanwu CU, Obi SKC, Okolo BN (2011) Lipopeptide biosurfactant production by Serratia marcescens NSK-1 strain isolated from petroleum-contaminated soil. J Appl Sci Res 7:79-87

Aparna A, Srinikethan G, Smitha H (2012) Production and characterization of biosurfactant produced by a novel Pseudomonas sp. 2B. Colloids Surf B Biointerfaces 95:23-29. https://doi.org/10.1016/j.colsurfb.2012.01.043

Arima K, Kakinuma A, Tamura G (1968) Surfactin, a crystalline peptidelipid surfactant produced by Bacillus subtilis: isolation, characterization and its inhibition of fibrin clot formation. Biochem Biophys Res Commun 31:488-494

Bak F, Bonnichsen L, Jørgensen NO, Nicolaisen MH, Nybroe O (2015) The biosurfactant viscosin transiently stimulates $n$ hexadecane mineralization by a bacterial consortium. Appl Microbiol Biot 99:1475-1483

Bento FM, De Oliveira Camargo FA, Okeke BC, Frankenberger WT (2005) Diversity of biosurfactant producing microorganisms isolated from soils contaminated with diesel oil. Microbiol Res 160:249-255. https://doi.org/10.1016/j. micres.2004.08.005

Berti AD, Greve NJ, Christensen QH, Thomas MG (2007) Identification of a biosynthetic gene cluster and the six associated lipopeptides involved in swarming motility of Pseudomonas syringae pv. tomato DC3000. J Bacteriol 189:6312-6323. https://doi.org/10.1128/JB.00725-07

Bodour AA, Miller-Maier RM (1998) Application of a modified drop-collapse technique for surfactant quantitation and screening of biosurfactant-producing microorganisms. J Microbiol Meth 32:273-280. https://doi.org/10.1016/ S0167-7012(98)00031-1

Bodour AA, Drees KP, Maier RM (2003) Distribution of biosurfactant-producing bacteria in undisturbed and contaminated arid southwestern soils. Appl Environ Microbiol 69:3280-3287. https://doi.org/10.1128/AEM.69.6.32803287.2003

Cameotra SS, Makkar RS (2004) Recent applications of biosurfactants as biological and immunological molecules. Curr Opin Microbiol 7:262-266

Cameotra SS, Makkar RS (2010) Biosurfactant-enhanced bioremediation of hydrophobic pollutants. Pure Appl Chem 82:97-116

Campos JM, Montenegro Stamford TL, Sarubbo LA, de Luna JM, Rufino RD, Banat IM (2013) Microbial biosurfactants as additives for food industries. Biotechnol Prog 29:1097-1108. https://doi.org/10.1002/btpr.1796

Chakraborty T, Chakraborty I, Ghosh S (2011) The methods of determination of critical micellar concentrations of the amphiphilic systems in aqueous medium. Arab J Chem 4:265-270. https://doi.org/10.1016/j.arabjc.2010.06.045

Cooper DG, Goldenberg BG (1987) Surface-active agents from two Bacillus species. Appl Environ Microbiol 53:224-229.

Cooper DG, Zajic JE (1980) Surface-active compounds from microorganisms. Adv Appl Microbiol 26:229-253. https:// doi.org/10.1016/S0065-2164(08)70335-6

D'aes J, De Maeyer K, Pauwelyn E, Höfte M (2010) Biosurfactants in plant-Pseudomonas interactions and their importance to biocontrol. Environ Microbiol Rep 2:359-372. https://doi.org/10.1111/j.1758-2229.2009. 00104.x

Das K, Mukherjee AK (2007) Crude petroleum-oil biodegradation efficiency of Bacillus subtilis and Pseudomonas aeruginosa strains isolated from a petroleum-oil 
contaminated soil from North-East India. Bioresour Technol 98:1339-1345. https://doi.org/10.1016/j.biortech. 2006.05.032

de Sousa T, Bhosle S (2012) Isolation and characterization of a lipopeptide bioemulsifier produced by Pseudomonas nitroreducens TSB.MJ10 isolated from a mangrove ecosystem. Bioresour Technol 123:256-262. https://doi. org/10.1016/j.biortech.2012.07.056

Desai JD, Banat IM (1997) Microbial production of surfactants and their commercial potential. Microbiol Mol Biol Rev 61:47-64. https://doi.org/10.1016/S0140-6701(97)845596

El Arbi A, Rochex A, Chataigné G, Béchet M, Lecouturier D, Arnauld S, Gharsallah N, Jacques P (2016) The Tunisian oasis ecosystem is a source of antagonistic Bacillus spp. producing diverse antifungal lipopeptides. Res Microbiol 167:46-57. https://doi.org/10.1016/j.resmic.2015.09.003

Fechtner J, Koza A, Sterpaio PD, Hapca SM, Spiers AJ (2011) Surfactants expressed by soil pseudomonads alter local soil-water distribution, suggesting a hydrological role for these compounds. FEMS Microbiol Ecol 78:50-58. https:// doi.org/10.1111/j.1574-6941.2011.01141.x

Gao J, Xie G, Peng F, Xie Z (2015) Pseudomonas donghuensis sp. nov., exhibiting high-yields of siderophore. Antonie Van Leeuwenhoek 107:83-94. https://doi.org/10.1007/ s10482-014-0306-1

Gomila M, Pena A, Mulet M, Lalucat J, García-Valdés E (2015) Phylogenomics and systematics in Pseudomonas. Front Microbiol. https://doi.org/10.3389/fmicb.2015.00214

Janek T, Łukaszewicz M, Rezanka T, Krasowska A (2010) Isolation and characterization of two new lipopeptide biosurfactants produced by Pseudomonas fluorescens BD5 isolated from water from the Arctic Archipelago of Svalbard. Bioresour Technol 101:6118-6123

Janek T, Lukaszewicz M, Krasowska A (2013) Identification and characterization of biosurfactants produced by the Arctic bacterium Pseudomonas putida BD2. Colloid Surf B 110:379-386

Karanth NGK, Deo PG, Veenanadig NK (1999) Microbial production of biosurfactants and their importance. Curr Sci 77:116-126

Khopade A, Biao R, Liu X, Mahadik K, Zhang L, Kokare C (2012) Production and stability studies of the biosurfactant isolated from marine Nocardiopsis sp. B4. Desalination 285:198-204. https://doi.org/10.1016/j.desal.2011.10.002

Kruijt M, Tran H, Raaijmakers JM (2009) Functional, genetic and chemical characterization of biosurfactants produced by plant growth-promoting Pseudomonas putida 267. J Appl Microbiol 107:546-556

Kuiper I, Lagendijk EL, Pickford R, Derrick JP, Lamers GE, Thomas-Oates JE, Lugtenberg BJJ, Bloemberg GV (2004) Characterization of two Pseudomonas putida lipopeptide biosurfactants, putisolvin I and II, which inhibit biofilm formation and break down existing biofilms. Mol Microbiol 51:97-113

Lang S (2002) Biological amphiphiles (microbial biosurfactants). Curr Opin Colloid Interface Sci 7:12-20

Lang S, Wullbrandt D (1999) Rhamnose lipids-biosynthesis, microbial production and application potential. Appl Microbiol Biot 51:22-32
Marchant R, Banat IM (2012) Microbial biosurfactants: challenges and opportunities for future exploitation. Trends Biotechnol 30:558-565

Martinez-Toledo A, Rios-Leal E, Vázquez-Duhalt R, GonzálezChávez MDC, Esparza-Garcia JF, Rodriguez-Vazquez R (2006) Role of phenanthrene in rhamnolipid production by $P$. putida in different media. Environ Technol 27:137-142

Merino E, Barrientos A, Rodríguez J, Naharro G, Luengo JM, Olivera ER (2013) Isolation of cholesterol-and deoxycholate-degrading bacteria from soil samples: evidence of a common pathway. Appl Microbiol Biot 97:891-904

Mnif I, Sahnoun R, Ellouz-Chaabouni S, Ghribi D (2017) Application of bacterial biosurfactants for enhanced removal and biodegradation of diesel oil in soil using a newly isolated consortium. Process Saf Environ Prot 109:72-81. https://doi.org/10.1016/j.psep.2017.02.002

Mohammed IU, Deeni Y, Hapca SM, McLaughlin K, Spiers AJ (2015) Predicting the minimum liquid surface tension activity of pseudomonads expressing biosurfactants. Lett Appl Microbiol 60:37-43. https://doi.org/10.1111/lam. 12331

Morikawa M, Daido H, Takao T, Murata S, Shimonishi Y, Imanaka T (1993) A new lipopeptide biosurfactant produced by Arthrobacter sp. strain MIS38. J Bacteriol 175:6459-6466

Morikawa M, Hirata Y, Imanaka T (2000) A study on the structure-function relationship of lipopeptide biosurfactants. Biochim Biophys Acta 1488:211-218. https://doi. org/10.1016/S1388-1981(00)00124-4

Mukherjee AK (2007) Potential application of cyclic lipopeptide biosurfactants produced by Bacillus subtilis strains in laundry detergent formulations. Lett Appl Microbiol 45:330-335. https://doi.org/10.1111/j.1472-765X.2007. 02197.x

Mulet M, Sánchez D, Lalucat J, Lee K, Garcia-Valdes E (2015) Pseudomonas alkylphenolica sp. nov., a bacterial species able to form special aerial structures when grown on $p$ cresol. Int J Syst Evol Microbiol 65:4013-4018. https://doi. org/10.1099/ijsem.0.000529

Müller MM, Kügler JH, Henkel M, Gerlitzki M, Hörmann B, Pöhnlein M, Syldatk C, Hausmann R (2012) Rhamnolipids-next generation surfactants? J Biotechnol 162:366-380

Mulligan CN (2005) Environmental applications for biosurfactants. Environ Pollut 133:183-198

Neu TR, Härtner T, Poralla K (1990) Surface active properties of viscosin: a peptidolipid antibiotic. Appl Microbiol Biot 32:518-520

Nielsen TH, Sørensen D, Tobiasen C, Andersen JB, Christophersen C, Givskov M, Sørensen J (2002) Antibiotic and biosurfactant properties of cyclic lipopeptides produced by fluorescent Pseudomonas spp. from the sugar beet rhizosphere. Appl Environ Microb 68:3416-3423

Pacwa-Płociniczak M, Płaza GA, Piotrowska-Seget Z, Cameotra SS (2011) Environmental applications of biosurfactants: recent advances. Int J Mol Sci 12:633-654. https:// doi.org/10.3390/ijms12010633

Pacwa-Płociniczak M, Płaza GA, Poliwoda A, PiotrowskaSeget Z (2014) Characterization of hydrocarbon-degrading and biosurfactant-producing Pseudomonas sp. P-1 strain as 
a potential tool for bioremediation of petroleum-contaminated soil. Environ Sci Pollut R 21:9385-9395

Pauwelyn E, Huang C-J, Ongena M, Leclère V, Jacques P, Bleyaert P, Budzikiewicz H, Schaefer M, Höfte M (2013) New linear lipopeptides produced by Pseudomonas cichorii SF1-54 are involved in virulence, swarming motility, and biofilm formation. Mol Plant Microbe Interact 26:585-598. https://doi.org/10.1094/MPMI-11-120258-R

Peypoux F, Bonmatin JM, Wallach J (1999) Recent trends in the biochemistry of surfactin. Appl Microbiol Biotechnol 51:553-563. https://doi.org/10.1007/s002530051432

Raaijmakers JM, de Bruijn I, Nybroe O, Ongena M (2010) Natural functions of lipopeptides from Bacillus and Pseudomonas: more than surfactants and antibiotics. FEMS Microbiol Rev 34:1037-1062. https://doi.org/10.1111/j. 1574-6976.2010.00221.x

Rahman KSM, Thahira-Rahman J, Lakshmanaperumalsamy P, Banat IM (2002) Towards efficient crude oil degradation by a mixed bacterial consortium. Bioresour Technol 85:257-261. https://doi.org/10.1016/S0960-8524(02)00 $119-0$

Rodrigues L, Banat IM, Teixeira J, Oliveira R (2006) Biosurfactants: potential applications in medicine. J Antimicrob Chemother 57:609-618

Rokni-Zadeh H, Li W, Sanchez-Rodriguez A, Sinnaeve D, Rozenski J, Martins JC, De Mot R (2012) Genetic and functional characterization of cyclic lipopeptide WLIP production by rice rhizosphere isolate Pseudomonas putida RW10S2. Appl Environ Microb 78:4826-4834

Ron EZ, Rosenberg E (2001) Natural roles of biosurfactants. Environ Microbiol 3:229-236

Ron EZ, Rosenberg E (2002) Biosurfactants and oil bioremediation. Curr Opin Biotechnol 13:249-252

Roongsawang N, Washio K, Morikawa M (2011) Diversity of nonribosomal peptide synthetases involved in the biosynthesis of lipopeptide biosurfactants. Int $\mathrm{J}$ Mol Sci 12:141-172
Sachdev DP, Cameotra SS (2013) Biosurfactants in agriculture. Appl Microbiol Biotechnol 97:1005-1016. https://doi.org/ 10.1007/s00253-012-4641-8

Saikia RR, Deka S, Deka M, Banat IM (2012) Isolation of biosurfactant-producing Pseudomonas aeruginosa RS29 from oil-contaminated soil and evaluation of different nitrogen sources in biosurfactant production. Ann Microbiol 62:753-763. https://doi.org/10.1007/s13213-0110315-5

Tuleva B, Christova N, Jordanov B et al (2005) Naphthalene degradation and biosurfactant activity by Bacillus cereus 28BN. Zeitschrift fur Naturforsch 60:577-582

Tvrzova L, Schumann P, Spröer C, Sedláček I, Páčová Z, Sedo O, Zdrahal Z, Steffen M, Lang E (2006) Pseudomonas moraviensis sp. nov. and Pseudomonas vranovensis sp. nov., soil bacteria isolated on nitroaromatic compounds, and emended description of Pseudomonas asplenii. Int $\mathrm{J}$ Syst Evol Microbiol 56:2657-2663

Van Hamme JD, Singh A, Ward OP (2006) Physiological aspects. Part 1 in a series of papers devoted to surfactants in microbiology and biotechnology. Biotechnol Adv 24:604-620

Vater J, Kablitz B, Wilde C, Franke P, Mehta N, Cameotra SS (2002) Matrix-assisted laser desorption ionization-time of flight mass spectrometry of lipopeptide biosurfactants in whole cells and culture filtrates of Bacillus subtilis C-1 isolated. Appl Environ Microbiol 68:6210-6219. https:// doi.org/10.1128/AEM.68.12.6210

Weekers F, Jacques P, Springael D, Mergeay M, Diels L, Thonart P (1999) Improving the catabolic functions of desiccation-tolerant soil bacteria. Appl Biochem Biotechnol 77-79:251-266

Youssef NH, Duncan KE, Nagle DP, Savage KN, Knapp RM, McInerney MJ (2004) Comparison of methods to detect biosurfactant production by diverse microorganisms. J Microbiol Methods 56:339-347 